\title{
Students-as-producers: Developing valuable student-centered research and learning opportunities
}

\author{
Hynes, Mike $\bowtie$ \\ National University of Ireland Galway, Ireland (mike.hynes@nuigalway.ie)
}

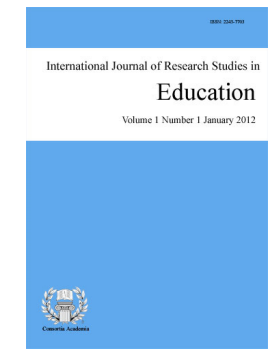

Accepted: 17 July 2017

ISSN: 2243-7703 Online ISSN: 2243-7711

OPEN ACCESS

\section{Abstract}

The desire to connect teaching and research to create a productive and progressive framework for student learning has become one of the most significant spaces for academic development in Higher Education over the recent past. The positive effects on student learning through the inclusion of real-life, complex and unstructured research-like activities needs to be at the core of undergraduate education, and following this paradigm the student acts as producer of knowledge instead of simply knowledge consumer. The concept underpinning 'student-as-producer' is that learning is grounded in research and research-like activities so much of what the student learns will be through their own discoveries, working in collaboration with academic advisers and other students in a supportive research-rich environment. This paper focuses on the research practices and activities during a study carried out by undergraduate students from the School of Political Science and Sociology at the National University of Ireland Galway, primarily designed as a student-as-producer project, under the guidance of an academic supervisor/facilitator. Students were placed at the center of deliberations, design, development and implementation of the research and subsequently have become the focus of this particular reflective paper. What were their experiences at various stages of the process, what do they think were worthwhile and valueless in the practice, and what learning principles, if any, were paramount? A series of semi-structured open questions were posed to uncover pressures and barriers to their overall learning experiences resulting in some thoughtful and helpful lessons to enhance such student-centered learning in the future.

Keywords: student-as-producer; student-centered learning; knowledge; higher education; teaching and research 


\section{Students-as-producers: Developing valuable student-centered research and learning opportunities}

\section{Introduction}

Teaching in Higher Education is often described as intellectually challenging but also an innovative practice. In more traditional approaches to university teaching most time is spent lecturing and the student remains broadly passive; listening and watching. Students then work independently on assignments and cooperation during class time is discouraged. This is a form of directed learning - the student is given instruction with the teacher the expert source of this particular knowledge - which has been synonymous with third level education in the past (Light, Calkins, \& Cox, 2009). But this teacher-focused, transmission of information format has become increasingly criticized paving the way for the growth of 'student-centered learning' as an alternative approach (Jonassen \& Easter, 2012; McMahon \& O'Neill, 2005; Race, 2015). Adopting a conceptual change, a student-centered approach to teaching is more likely to lead to high quality student learning and to greater teaching satisfaction than the adoption of an information transmission, teacher-focused approach (Keith Trigwell \& Prosser, 2004). With student-centered learning, what the student does is as important for their understanding as what the teacher tells them. Students create knowledge as opposed to passively receiving information, and this encourages deep learning. Moreover, recent attempts to restate the meaning and purpose of Higher Education focuses on reconnecting the core activities of universities - research and teaching - in a way that consolidates and validates the values of academic life has led to the development of 'student-as-producer' (cf: Neary \& Winn, 2009) rather than 'student as consumer' (cf: McMillan \& Cheney, 1996) approaches to collaboration in the production of knowledge. The student-as-producer model advocates a pedagogical approach that appreciates the student voice, choice and creativity so that they can recognize themselves in a world of their own design and take responsibility for their own learning. Research-engaged teaching is grounded in the intellectual history and tradition of the modern university and the creation of a research environment that includes undergraduate students is a critical way of linking undergraduate teaching and research (Neary \& Winn, 2009).

This paper seeks a better understanding of the conditions and arrangements needed to undertake a successful student-as-producer project in Higher Education. A particular existing taught module of interest, which lacked practical hands-on elements, was first identified. In seeking to provide an enhanced understanding of social scientific research methods to undergraduate students at the National University of Ireland Galway this student-centered approach was employed to accomplish a cooperative teacher/student research project over the summer of 2016. A general request to first and second year students undertaking the Political Sciences and Sociology modules - part of the Bachelor of Arts Joint Honors degree program - to participate in a research project from design to dissemination was made at the beginning of May of that year. Overall, nine students agreed to participate in this voluntary research initiative. The author's role in the process was to facilitate and offer support and advice, and afford some necessary leadership at the beginning of the project. While some direction was anticipated to be required in designing the questionnaire, many of the processes thereafter were expected to be left to the participants to decide and agreed upon collectively. This paper is an attempt to nuance the particular experiences of these students throughout the project and uncover any pressures or barriers that may exist to the development of this pedagogical approach to student-centered learning in the future. Eight of the nine participants responded anonymously to eight semi-structured open questions ${ }^{1}$ about their involvement and overall learning opportunities and experiences throughout the project and this has resulted in an appreciation and enriched understanding of the measures and practices deemed necessary for such student-as-producer research projects to be more successful in the future.

\footnotetext{
${ }^{1}$ These eight questions are provided in the appendix.
} 


\section{The Literature: Refocusing on Student Learning}

The Higher Education sector continues to experience significant challenges and reforms worldwide. The past decades have seen a steady increase in student numbers, further internationalization of the student population, and a wider diversity in the prior education experiences of students (Fry, Ketteridge, \& Marshall, 2009). While these pressures form an inescapable backdrop to debates and discussions about advancing teaching in Higher Education, a crucial aspect to improved teaching in the sector comes from studying student learning (Ramsden, 1992). Thus, in many ways the aim of teaching at third level is straightforward; make student learning possible. Mindful of this, students can be perceived to use one of three broad approaches to learning; surface, deep, and strategic (Cannon \& Newble, 2000; Entwistle \& Ramsden, 1983; Marton, Hounsell, \& Entwistle, 1984). Students adopting a surface approach to learning are predominantly motivated by a concern to complete the course or a fear of failure while, in contract, students adopting a deep approach are motivated by an interest in the material and need to make sense of things and interpret knowledge. Students demonstrating a strategic approach, while appearing to use processes similar to both surface and deep learning, fundamentally differ in their motivation and intention. The outcomes most hoped for from a university or college education are those resulting from the deep approach where students 'feel themselves to be the agents of learning' (Manton, 1975, p. 137). Given its emphasis on meaning making and the relationship to personal experience, deep or transforming categories of learning are more closely associated with abilities to successfully perform (Light, Calkins, \& Cox, 2009). Lecturers who take a student-centered approach to teaching and learning encourage students to adopt this deep approach (Prosser \& Trigwell, 1999; Trigwell, Prosser, Ramsden, \& Martin, 1998).

Developing a student-focused classroom can be challenging and it compels teachers to focus more on the needs of the students and less on what is easy, comfortable or familiar (Hannay, Kitahara, \& Fretwell, 2010). The teacher must focus on techniques to promote student learning using the principles of active learning and apply new arrangements and technologies. The role of 'Sage-on-the-stage' as the dominant model of teaching needs to shift to 'Meddler-in-the-middle' which 'positions the teacher and student as mutually involved in assembling and dis-assembling cultural products' (McWilliam, 2008, pp. 265-266). The key aspects of student engagement in Higher Education are finding the means to incorporate student intellect in the quality processes for teaching and learning activities (Hagyard, 2009). Student-centered learning methods shift the focus of activity away from the teacher to the learners and this paradigm shift from information transfer teaching to an emphasis on learning has permitted power to be transferred from the teacher to the student (Barr \& Tagg, 1995). This develops learner autonomy and independence by putting responsibility for the learning path directly in the hands of students (Jones, 2007; Pedersen \& Liu, 2003). Student-centered learning theory and practice are based on constructivist learning theory that emphasizes the learner's critical role in constructing meaning from new information and prior experience. According to constructivists, meaning is derived from and interpreted through individual beliefs, experiences, and social contexts thus; individual meaning is actively constructed through personal interactions with the world rather than assimilations (Biggs \& Moore, 1993; Phillips, 1995).

The need to link research and teaching to create a creative and enlightened framework for undergraduate teaching and learning has become 'one of the most significant developments in thinking about teaching and learning in Higher Education in recent years' (Jenkins, Breen, Lindsay, \& Brew, 2003, p. ix). Grounded in a pedagogy derived from Marxist social theory (Dinerstein, 2015; Postone, 1993), student-as-producer provides a response to the broad changes and challenges in Higher Education which have shifted the focus from a liberal arts core to an entrepreneurial periphery, increasing the 'marketization' of the academy and detailing the rise of research and development (R\&D) with commercial purpose (Slaughter \& Leslie, 1997, p. 208). Neary and Winn (2009) maintain the positive impacts on student learning through the inclusion of real, complex and unstructured research-like activities needs to be at the core of undergraduate education, and following this paradigm the student acts as producer of knowledge instead of simply knowledge consumer. The concept behind student-as-producer is that student learning is grounded in research and research-like activities so that much of what the student learns will be through their own discoveries, working in collaboration with academic advisers 
and other students in a research-rich environment. The aim should be 'to increase the circumstances in which teaching and research have occasion to meet, and to provide rewards not only for better teaching or for better research but also for demonstrations of the integration between teaching and research' (Hattie \& Marsh, 1996, p. 533).

Student-as-producer has gained international recognition as a model of good practice and has been taken up in many adapted forms by universities and colleges worldwide (Hagyard \& Watling, 2010; Neary, 2016; Neary, Saunders, Hagyard, \& Derricott, 2015). Dialogic learning environments characterized by respectful collaboration and open-ended learning opportunities motivates and engages learners (Bovill, 2014; Hodge, Haynes, LePore, Pasquesi, \& Hirsh, 2008). Furthermore, studies have demonstrated strong, positive student perceptions of staff research and student perceptions of staff involvement in research incorporated into their teaching made students perceive their courses as up-to-date and intellectually stimulating (Jenkins, Blackman, Lindsay, \& Paton-Saltzberg, 1998; Neumann, 1994). For many academics also, there is strong belief that quality teaching is functionally dependent on the lecturer being directly involved in research (Jenkins et al., 2003). However, Elton (2001) argues that a positive research and teaching link largely depends on the nature of the students' learning experiences, resulting from appropriate teaching and learning processes rather than on particular outcomes or inputs. To understand these effective linkages we need improved scholarly evidence on student and staff motivations and their experiences with such student-as-producer approaches.

\section{Setting the Scene}

The author co-teaches on the Research Methods for the Social Science (SP220) module in the second semester of year two of the Bachelor of Arts Joint-Honors Degree program at the National University of Ireland Galway. The overall aim of this module is to enable students appreciate what sociological and political data are, how to critically interpret them and, how to use them effectively in their own future research work. The module is broken into two distinct streams of study; qualitative and quantitative research methods, with the author's personal teaching responsibilities focused on the latter. The quantitative stream of SP220 covers the fundamentals of survey research including; issues of operationalization, questionnaire design, sampling, and basic statistical analysis methods. In addition, students learn statistical literacy skills that enable them to read and understand statistical evidence presented in the media and official publications. The module consists of 24 lecture hours, 12 quantitative and 12 qualitative lectures. Student numbers on this module are high ${ }^{2}$ and this necessitates that all instruction, teaching and learning activities take place in one of the large on-campus lecture theatres. SP220 is assessed at the end of the semester by means of a two-hour examination covering all aspects of the course material. This examination is broken into two sections. Part A focuses on the quantitative stream and consists of 50 multiple-choice questions. Part B concentrates on the qualitative stream and entails writing two short essays from a possible nine options provided. The author has had increasing concerns about the levels of non-attendance at lectures and, indeed, lack of engagement with the subject material throughout the semester.

The primary role of a teacher or lecturer in Higher Education is to enable students engage, learn and understand the relevant material and thus appreciate the long-term value of deep learning. Having a high non-attendance rate coupled with the lack of engagement with the material translates to a failure of teaching leading to an unsatisfactory learning environment. This realization provided the impetus for focusing on change related to the practical connection of the material taught at lectures with tangible research design processes and outcomes. Students gain a better understanding of the material if it becomes applied and 'real-world'. These concerns led to a general call for participation in a practical research project to all first and second year students on the Bachelor of Arts Joint-Honors Degree program registered on the university's Blackboard system. Nine students responded to the call for voluntary participants, the aim of which was to design a project from concept to dissemination, a process facilitated by the author. An initial meeting was arranged to outline the aims and

\footnotetext{
${ }^{2}$ For the 2016/2017 academic year 317 students were registered on the SP220 module.
} 
Students-as-producers: Developing valuable student-centered research and learning opportunities

objectives and thus began the preliminary, voluntary student-as-producer research project over the summer months of 2016. It was anticipated that the author's role would be to facilitate and supervise the early meetings and provide some direction and advice in designing the questionnaire. Thereafter, it was expected that the students would perform as a team with limited oversight to complete the data collection and engage with the dissemination of results and outcomes. Knowles' (1984) process model views the effective facilitator as someone who ensures students are cognizant of what is expected of them and have sufficient capacity to take ownership of their learning. Students often interpret their lecturer's facilitation as that of a silent manager, reflecting a pedagogical shift towards a more balanced and shared relationship (McCabe \& O'Connor, 2014).

The objective of the research project sought to capture people's opinions and understanding of transport, mobility and liveability in Galway City, Ireland. Liveability refers to all the things that add up to a good community life including the design of neighborhoods, the natural environment, economic prosperity, social stability and equity, educational opportunities, and good cultural, entertainment and recreation facilities. Transport is also central to facilitating urban liveability and mobility and transport systems should be designed to be adaptable and attractive and aim to promote health and wellbeing, safety and accessibility. Data collection was carried out by the undergraduate students over the summer months of June, July and August 2016. Galway is a city on the west coast of Ireland in the province of Connacht with a population of 79,504 (CSO, 2016) and thus is an ideal site for investigating issues of transport and liveability as these relate to small cities and towns. The team has already disseminated some results and findings; others wait to be finalized over the coming months. While this project was interesting in its own right, ${ }^{3}$ the focus of this particular paper is a better understanding of the processes that helped or hindered the student learning experience over the course of the project. The participants were asked eight semi-structured questions via the online open source Limesurvey platform and they were encouraged to elaborate on any aspect that they felt assisted or obstructed their own personal learning experience. Eight participants completed the questionnaire offering some insightful and perceptive feedback on their involvement with the project. The resulting data was analyzed using a grounded theory approach in which some important concepts and themes emerged after a number of iterative reviews of the responses. Grounded theory (GT) is a systematic methodology in the social sciences involving the construction of theory through the analysis of data (Martin \& Turner, 1986).

\section{How the Students Fared}

So, how did the participants fare throughout the process and what, if any, were their learning experiences? The participant's responses to the eight questions were evaluated and analyzed at the end of the data collection period and the resulting analyses is provide here. The first question asked was if the students understood their roles in the project.

\subsection{Understanding their specific role and duties in the project?}

Overall, most participants understood what the project work entailed, although some had distinctive focuses and goals:

The objective of the student, who took a part in the project is to foster an interest in social relation and environment research such as; good community life and neighborhoods, the natural environment, economic prosperity, social stability and equity and educational opportunities. Also, students understand the role in research processes, collecting data, techniques and methodologies and the opportunity to gain practical experience of research by conducting a small research project under the supervising of [the lecturer] (participant two)

\footnotetext{
${ }^{3}$ Further information about the project can be found on the Social Science Research Centre (SSRC) website at www.ssrc.ie.
} 
Yes. Process was very structured and clear. [The lecturer] was always available to talk to regarding role and its flexibility (participant four)

Yes I think so, even though I joined the team after the project had started, I met with [the lecturer] and he explained to me how the project was going to work. My understanding of the project is that we are trying to identify what people of Galway think about transport, mobility and the liveability in this town (participant five)

Yes I understood that it was to give me an understanding about how to work in a team and to experience the challenges of research (participant eight).

However, as the projected progressed some confusion ensued as to the participant's exact roles, tasks and responsibilities needed to complete the process:

I thought I did, but as the project went on I became more and more unsure about everyone's role. I knew what the project was about, but I felt that so many others in the group seemed to have a different idea. That caused confusion (participant one)

A number of participants expressed concern about the lack of clear structure and what was required for practical dissemination of the results. The writing-up of results was highly problematic and many students shied away from this particular aspect of the project:

Yes I understood what the project was about, and was happy to be part of the team. I would have preferred if the roles had been more structured. However, I personally was limited in fully participation due to health and time constraints (participant six)

Yes insofar as distributing and collecting data. The write up was less clear cut as we weren't really pushed to read the papers or to do any extra reading. Even though [the lecturer] did indicate it wasn't direct enough. Just too easy going :) maybe that's just me I don't know. I actually never read the papers because It wasn't made necessary (participant seven)

4.2 Student learning during the course of the project?

Participants were then asked what, if anything, they had learnt from the project and the process they had engaged with. Again, some positive feedback on tangible student learning was expressed by individuals:

I learned how to set up a quantitative research project. To start the research we did set up a research questionnaire, the types of information we needed. Then, selected samples to a general population, methods of data collection, how to collect data and how to access these sources of information (participant two)

A broader understanding and a more practical approach to getting a grasp on the methods used in research. It is a good grounding for future research and also research methods as a subject. We can relate to topics covered in class with our practical experience (participant three)

I learned that it's not easy putting a project/research together (coming up with the right questions what to ask without being too intrusive) (participant six)

The practical side of the research taught me a lot more than what I would get from a book (participant seven)

Yes I learned the different approaches to people and how to maintain subtlety when dealing with the subject (participant eight)

Team-working is an significant and important skill and attribute that some students appreciated during the 
Students-as-producers: Developing valuable student-centered research and learning opportunities

project. In addition, there was attention to the academic outputs from the research for one student:

I did learn a lot. Firstly $i$ got the chance to prove to myself that $i$ can work in a team, improved my confidence and communication skills when asking people to fill our surveys, learn to read the data presented in different types of graphs, the whole project has been a learning curve for me as $i$ want to do a research PhD in the future (participant five)

It was an introduction to the general structure of how an academic paper is created and drafted. Learning the stages it goes through before being published was also a very important aspect of academic writing to learn, one that often goes unmentioned elsewhere (participant four)

However, another contributor had difficulty with the initial discussions and debates around the concepts the team employed in the research, and the team-working required to successfully complete the project, and this led to a level of frustration for that student:

I learned that I should [have] made my voice heard more, because so much time was wasted, or so many clearly pointless avenues of discussion were pursued (participant one)

4.3 What would the student have done differently in the project?

The participants were then asked what, if anything, they would have done differently. Once again, the issue of structure and the division of specific tasks and responsibilities within a specific agreed timeframe became evident:

Have the group more strictly led in terms of veering wildly off topic (participant one)

Well $i$ can't think of anything really but maybe a better and clear division of work among the team members?! (participant five)

Yes. $i$ think we were not meeting enough, and that it may have worked better if each person had a particular role (participant six)

One student had a view that allowing the students less freedom would have created an environment more conductive to the success of the project, and increased overall student learning during the project:

Don't say no pressure, in student language that means don't bother doing it you don't have to.

Don't say in your own time, that means if you have time and if not no worries. don't meet in coffee shops or in the staff room - it can be good to have formal and informal parts but to get us work orientated it's better to have it in a classroom setting. Of course sometimes we would benefit from meeting for coffee discussing everything with no agenda and see what comes out of that too (participant seven)

4.4 With regards to the autonomy afforded the students, how did they feel about this?

Participants were then asked specifically about the structure of the project and did they appreciate the freedom given. Views were somewhat mixed on this question:

Tasks and workload became more clearly defined as the project went on, however, this coincided with the beginning of term, which meant the project takes a back seat (participant one)

It was a well-structured project, but I would prefer more time-framed way and more demands on the students. The freedom given here could be less productive (participant two)

I did appreciate the freedom given as I'm a final year student, but $i$ would have preferred a bit more structure (participant five) 
I appreciated the freedom given from the start, but I personally would have liked to have had a task/s clearly outlined from the beginning. So, that each person on the team personal strengths could have been utilized more beneficially on the project (participant six)

More structure coming from someone who likes freedom but it doesn't work in this situation (participant seven)

I preferred the freedom given as for me I find it difficult to be fenced in (participant eight)

4.5 What parts of the project was most difficult or problematic?

The participants were further asked; what part, if any, of the project did they find most difficult or problematic? A number of students responded that the actual data collection process caused them some anxiety and difficulty:

Door-to-door data collection. I felt uncomfortable to intervene in someone's privacy or private property (participant two)

Some people were rude, kept asking personal questions, others weren't happy with how the questions were [phrased]. However, this can happen to anyone so I got used to it and tried to answer them as well as I could (participant five)

I felt that cold calling to the houses was problematic due to the nature of people not liking been disturbed. I felt that if they would not fill out the Questionnaire within a short time frame give to them (within the hour or so), when I went back to the house to collect the forms later that evening or within the time fame I give them (two days) a few households said they would send it into the college later themselves which they did not which was disappointing (participant six)

In addition, some students found time-management to be a problem they needed to contend with. In fact, time issues led to most students concluding their involvement in the project before the writing-up of results:

The timing of the write up clashing with assignments and exams... we had all summer to do it better and get it finished sooner :) (participant seven)

Organizing people to be free at the same time (participant eight)

I found the prospect of calling door to door to be very intimidating (participant one)

4.6 The levels of commitment required of students?

When asked if the project took up too much effort and the student's time over the summer months most replied that this was not an issue, although some were disappointed in their own commitment to the research:

Over the summer, no, but more was required during term time (participant one)

The project didn't take much of my time in the summer. I would like to participate in another project if it takes place in the summer time (participant two)

I feel I could have given it more effort. However, I was happy with what time I devoted to the project (participant six)

No in the sense we didn't have to do too much, yes in the sense that we could have done more with the time we did have (participant seven)

Not at all, it was great meeting up with fellow students and hanging out (participant eight) 
Students-as-producers: Developing valuable student-centered research and learning opportunities

4.7 Would the student participate in a similar project?

All the students responded that they would like to participate in a similar research project and were appreciative of the opportunity to contribute to the endeavor. Indeed, when asked to provide some final comments or remarks this appreciation of the learning experiences afforded was expressed:

Nothing further than previously stated, but I would like to add that it is a brilliant opportunity to experience a research project from the ground up, and in that sense, invaluable (participant one)

[The lecturer] has been a brilliant influence throughout all of this. As a lecturer, someone to talk to about the field and a mentor throughout the project, [the lecturer] has always made time for me and listened to everything. I've had to say it has been a great process and has really matured me, especially in realizing what is needed to keep up full time education along with participating in a project such as this. My goal now is continue to work to the point where I can satisfactorily maintain both (participant four)

I would just like to thank [the lecturer] for giving me the opportunity to be part of this learning and fun research (participant eight).

\section{Lessons Learnt}

Although there are many different reasons why faculty members in Higher Education choose to adopt student-centered learning approaches one of the key concerns for practitioners should be; do these approaches lead to improvements in overall student learning and performance. There has been a noticeable shift in teacher-student responsibilities as a result of the adoption of such approaches but the transition is not always easy and any change in practice should involve a degree of risk and uncertainty. In particular, the lecturer needs to have confidence in the students' ability and competence to think and learn for themselves. There is much to be learnt about student-centered approaches from the experiences of lecturers and students undertaking such approaches in real-world conditions. This particular paper sought to better understand and evaluate a student-centered approach that took place over the summer months of 2016 in which a student-as-producer methodology was adopted for a voluntary research project that was undertaken by undergraduate student. So, what were the lessons learnt so that future similar projects and compatible undertakings can benefit from the unique insight of those students who took part in this particular research endeavor?

One of the central concerns expressed by participants was the absence of a more robust structure, lack of direction or leadership, and the independence afforded the students during the project. While the author did facilitate many of the early discussions and, indeed, provide some direction on the concepts and a number the questions for the survey, full autonomy was then granted to the team during the data collection process. This led to some difficulty for those involved and resulted in the corrosion of motivation for individuals and eventual the entire team. The effectiveness of group work as a learning structure is likely to be affected by the composition of the group and it is important that group work exercises include a reflective component to allow students to reconcile their individual contributions and interactions with the final group achievement (Livingstone \& Lynch, 2000). Indeed, groups sometimes find it difficult to manage agreement and define roles, which can have negative consequences for the functioning of the group (Garavan, Hogan, \& Cahir-O'Donnell, 2003). Group formation and teambuilding was not prioritized at the beginning of this project leading to diminished motivation and conflict. This further led to the temporary shelving of some of the project outputs. However, this is a crucial aspect of any project and students need to be made aware of the need for continuous engagement with the material until it has been satisfactorily disseminated. It became evident that the project required a 'firmer' hand with regards to participant expectation and the allocation of tasks needed to successful complete the tasks, and the author is culpability in this respect. While it was felt that students would benefit more for high levels of autonomy and less hierarchical control over many parts of the process, the necessary team-working skills and 
experience were not present for a consensus to be arrived at. Indeed, this will need to be impressed upon students in future projects; group and team-working is a significant and important learning outcome from any project work. More thought about the roles and responsibilities of each participant is required prior to the project commencement, and these also need to be communicated to individuals and the entire project team. Indeed, motivation and time-management were issues, and at time highly problematic, for many of the students and these concerns need to be comprehensively addressed in forthcoming student-as-producer research projects.

Participants articulated different levels of learning throughout the process. All the respondents felt that they had achieved some new understanding of research methods or, indeed, what is required and necessary to undertake an academic research project from concept to dissemination. Much of this new learning and understanding students could relate to particular aspects of the course or their understanding of similar research methods courses in other disciplines such as Psychology. In addition, students received first-hand practical experience of data collection for social scientific research and developed a deeper appreciation of the issues and potential problems of this particular part of the process. One heartening reaction from all the participants that responded to the semi-structured questionnaire was that all would join a similar project sometime in the future. However, if lessons are to be learnt such projects will need to be managed in a more efficient manner with clearly defined roles and responsibilities to be carried out within a clearly define timeframe. Thus, the learnings for future comparable student-as-producer research projects can be summarized as:

$>\quad$ Provide sufficient time at the beginning of the project for teambuilding and group formation and impress upon students that this is an important learning outcome

$>\quad$ Collectively agree roles and tasks to be undertaken to successfully complete the project

$>\quad$ Agree upon a specific pre-determined timeframe for each element of the project

$>$ Impress upon the students the need to disseminate the results of the project.

\section{Conclusions}

In meeting the contemporary challenges of teaching in Higher Education, a key motivating factor for many is that of encouraging greater student engagement in and responsibility for their own learning. This particular project afforded students the opportunity to design a body of research from concept to dissemination and gain hands-on practical experience of what this entailed. This student-centered approach sought to engage students in research, with an emphasis less on the content and more on the skill and processes needed. After identifying a particular module which has had, heretofore, a teacher-focused, transmission of information format, the author set about seeking participants in a more practical research project which shifted the focus from the teacher to the student to increase the possibility of student-centered learning. While this was an initial attempt at such an approach, some important lessons have been learnt for future such projects. The feedback from students participating in this project would suggest that while they enjoyed the process and did learn from their experiences, much more attention is needed with regards to outlining the roles and responsibilities for all participants. These need to be clearly defined to each team member and outlined to the group collective from the outset. Indeed, proving a defined timeframe, from start to finish, is also crucial to avoid the project petering out and creating conflict with student's other study, educational and home commitments. While the project has been wholly worthwhile, these lessons need to be learnt, acknowledged and incorporated into student-as-producer projects in the future. While acknowledging that this has been a somewhat crude first attempt at such a student-centered approach, the author and participants view similar such projects as exceptionally worthwhile and would welcome much more robust research in this area, which will provide valuable indicators to the success, or otherwise, of such projects in the future. 


\section{References}

Barr, R. B., \& Tagg, J. (1995). From teaching to learning: A new paradigm for undergraduate education. Change. The Magazine of Higher Learning, 27(6), 12-26. https://doi.org/10.1080/00091383.1995.10544672

Biggs, J. B., \& Moore, P. J. (1993). The process of learning. New York, NY: Prentice-Hall.

Bovill, C. (2014). An investigation of co-created curricula within higher education in the UK, Ireland and the USA. Innovations in Education and Teaching International, 51(1), 15-25. https://doi.org/10.1080/14703297.2013.770264

Cannon, R., \& Newble, D. (2000). A handbook for teachers in universities and colleges: A guide to improving teaching methods (4th ed.). London, UK and New York, NY: RoutledgeFalmer.

CSO. (2016, October 9). Population and actual and percentage change 2011 to 2016 by sex, province county or city, census year and statistics. Retrieved from http://www.cso.ie/en/releasesandpublications/ep/p-cpr/censusofpopulation2016-preliminaryresults/geoc $\underline{\text { han }}$

Dinerstein, A. C. (2015). The politics of autonomy in Latin America: The art of organizing hope. London, UK and New York, NY: Palgrave Macmillan. https://doi.org/10.1057/9781137316011

Elton, L. (2001). Research and teaching: conditions for a positive link. Teaching in Higher Education, 6(1), 43-56. https://doi.org/10.1080/13562510020029590

Entwistle, N., \& Ramsden, P. (1983). Understanding student learning. London, UK: Croom Helm.

Fry, H., Ketteridge, S., \& Marshall, S. (2009). A handbook for teaching and learning in higher education: Enhanced academic practice (3rd ed.). New York, NY and London, UK: Routledge.

Garavan, T.N., Hogan, C., \& Cahir-O'Donnell, A. (2003). Making training and development work: A best practice guide. Cork, Ireland: Oak Tree Press.

Hagyard, A. (2009). Student intelligence: Challenging received wisdom in student surveys. In L. Bell, H. Stevenson, \& M. Neary (Eds.), The future of higher education: Policy, pedagogy and the student experiences (pp. 112-125). London, UK and New York, NY: Continuum International Publishing Group.

Hagyard, A., \& Watling, S. (2010). The student as producer: Learning by doing research. In P. Hartley, J. Hilsdon, C. Keenan, S. Sinfield, \& M. Verity (Eds.), Learning development in higher education (pp. 169). Hampshire, UK: Palgrave Macmillan.

Hannay, M., Kitahara, R., \& Fretwell, C. (2010). Student-focused strategies for the modern classroom. Journal of Instructional Pedagogies, 2(1), 1-16.

Hattie, J., \& Marsh, H. W. (1996). The relationship between research and teaching: A meta-analysis. Review of Educational Research, 66(4), 507-542. https://doi.org/10.3102/00346543066004507

Hodge, D., Haynes, C., LePore, P., Pasquesi, K., \& Hirsh, M. (2008, June 25-27). From inquiry to discovery: Developing the student as scholar in a networked world. Paper presented at the 3rd Learning Through Enquiry Alliance (LTEA) Conference, University of Sheffield, UK.

Jenkins, A., Blackman, T., Lindsay, R., \& Paton-Saltzberg, R. (1998). Teaching and research: Student perspectives and policy implications. Studies in Higher Education, 23(2), 127-141. https://doi.org/10.1080/03075079812331380344

Jenkins, A., Breen, R., Lindsay, R., \& Brew, A. (2003). Reshaping teaching in higher education: Linking teaching with research. London, UK and Sterling, VA: Kogan Page Limited. https://doi.org/10.4324/9780203416884

Jonassen, D. H., \& Easter, M. A. (2012). Conceptual change and student-centered learning environments. In D. H. Jonassen \& M. A. Easter (Eds.), Theoretical foundations of learning environments (2nd ed., pp. 95-113). New York, NY and Oxon, UK: Routledge.

Jones, L. (2007). The student-centered classroom. New York, NY: Cambridge University Press.

Knowles, M. (1984). The adult learner: A neglected species. Houston, TX: Gulf Publishing Co.

Light, G., Calkins, S., \& Cox, R. (2009). Learning and teaching in higher education: The reflective professional (2nd ed.). London, UK: Sage Publications Ltd. 
Hynes, M.

Livingstone, D., \& Lynch, K. (2000). Group project work and student-centred active learning: Two different experiences. Studies in Higher education, 25(3), 325-345. https://doi.org/10.1080/713696161

Manton, F. (1975). What does it take to learn? In N. J. Entwistle \& D. Hounsell (Eds.), How students learn. Lancaster, UK: Institute for Research and Development in Post Compulsory Education.

Marton, F., Hounsell, D., \& Entwistle, N. J. (1984). The experience of learning. Edinburgh, UK: Scottish Academic Press.

Martin, P. Y., \& Turner, B. A. (1986). Grounded theory and organizational research. The Journal of Applied Behavioural Science, 22(2), 141-157. https://doi.org/10.1177/002188638602200207

McCabe, A., \& O'Connor, U. (2014). Student-centred learning: The role and responsibility of the lecturer. Teaching in Higher Education, 19(4), 350-359. https://doi.org/10.1080/13562517.2013.860111

McMahon, T., \& O'Neill, G. (2005). Student-centered learning: What does it mean for students and lecturers? In G. O'Neill, S. Moore, \& B. McMullin (Eds.), Emerging issues in the practice of university learning and teaching (pp. 27-36). Dublin, Ireland: All Ireland Society for Higher Education (AISHE).

McMillan, J. J., \& Cheney, G. (1996). The student as consumer: The implications and limitations of a metaphor. Communication Education, 45(1), 1-15. https://doi.org/10.1080/03634529609379028

McWilliam, E. (2008). Unlearning how to teach. Innovations in Education and Teaching International, 45(3), 263-269. https://doi.org/10.1080/14703290802176147

Neary, M. (2016). Student as producer: The struggle for the idea of the university. Other Education, 5(1), 89-94.

Neary, M., Saunders, G., Hagyard, A., \& Derricott, D. (2015). Student as producer: Research-engaged teaching, an institutional strategy. Report for Higher Education Academy: York, UK.

Neary, M., \& Winn, J. (2009). The student as producer: Reinventing the student experience in higher education. The Future of Higher Education: Policy, pedagogy and the student experience (pp. 192-210). London: Continuum.

Neumann, R. (1994). The teaching-research nexus: Applying a framework to university students' learning experiences. European Journal of Education, 29(3), 323-338. https://doi.org/10.2307/1503744

Pedersen, S., \& Liu, M. (2003). Teachers' beliefs about issues in the implementation of a student-centered learning environment. Educational Technology Research and Development, 51(2), 57-76. https://doi.org/10.1007/BF02504526

Phillips, D. C. (1995). The good, the bad, and the ugly: The many faces of constructivism. Educational Researcher, 24(7), 5-12. https://doi.org/10.3102/0013189X024007005

Postone, M. (1993). Time, labour and social domination: A reinterpretation of Marx's critical social theory. Cambridge, UK: Cambridge University Press. https://doi.org/10.1017/CBO9780511570926

Prosser, M., \& Trigwell, K. (1999). Understanding learning and teaching. The experience in higher education. Buckingham, UK: The Society for Research into Higher Education and Open University Press.

Race, P. (2015). The lecturer's toolkit: A practical guide to assessment, learning and teaching (4th ed.). Oxon, UK and New York, NY: Routledge.

Ramsden, P. (1992). Learning to teach in higher education. London, UK and New York, NY: Routledge. https://doi.org/10.4324/9780203413937

Slaughter, S., \& Leslie, L., L. (1997). Academic capitalism. Baltimore, MY and London, UK: The John Hopkins University Press.

Trigwell, K., \& Prosser, M. (2004). Development and use of the approaches to teaching inventory. Educational Psychology Review, 16(4), 409-424. https://doi.org/10.1007/s10648-004-0007-9

Trigwell, K., Prosser, M., Ramsden, P., \& Martin, E. (1998). Improving student learning through a focus on the teaching context improving student learning (pp. 97-103). Oxford, UK: Oxford Centre for Staff and Learning Development. 
Appendix: Semi-structured questions posed to the student researchers:

1. Did you understand your role in the project? (please provide details)

2. What, if anything, did you learn from the project? (please provide details)

3. What would you have liked to do differently? (please provide details)

4. Would you have liked more structure to the project or did you appreciate the freedom given? (please provide details)

5. What part, if any, of the project did you find most difficult or problematic? (please provide details)

6. Did the project take too much effort and your time over the summer? (please provide details)

7. Would you consider participating in another similar project? (please provide details)

8. Would you like to provide any final comments or suggestions? 
Hynes, M. 